Copyright (C) 2015 by Academic Publishing House Researcher

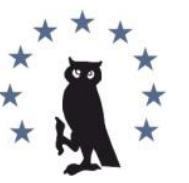

Published in the Russian Federation

European Researcher

Has been issued since 2010.

ISSN 2219-8229

E-ISSN 2224-0136

Vol. 101, Is. 12, pp. 762-774, 2015

DOI: 10.13187/er.2015.101.762

www.erjournal.ru

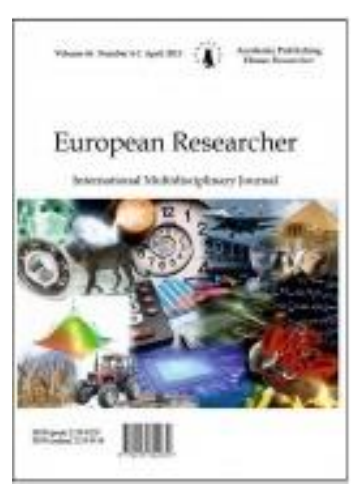

Economic sciences

Экономические науки

UDC 339.92

\title{
Pricing in the Market of fuel Agri-pellet in the System of the Sustainable Development
}

\author{
${ }^{1}$ Liubov P. Galperina \\ ${ }_{2}^{2}$ Liubov I. Lukianenko
}

\begin{abstract}
${ }^{1}$ Kyiv National Economic University named after Vadym Hetman, Ukraine
PhD (Economy), professor

E-mail: liubovgalperina@gmail.com

${ }^{2}$ Kyiv National Economic University named after Vadym Hetman, Ukraine

$\mathrm{PhD}$ (Economy), associate professor

E-mail:moia.kneu@ukr.net
\end{abstract}

\section{Abstract}

The article analyzes the pricing conditions in the domestic and export market agri-pellet taking into account qualitative characteristics of the fuel market, farm, natural, and institutional and regulatory factors. The comparative characteristic of agri-pellet prices with the prices of other fuels in the context of sustainable development (environmental, sustainability, calorific value, accessibility for the population, as well as energy security). Analyzed the complexity of the formation and development of the internal market demand fuel agri-pellets. The importance of state support for domestic consumption and agropellet determining price targets using the "green" tariff. Priority actions should include: the improvement of the mechanism of the use of "green" tariff for bioenergy, conversion of the CHP in order to use fuel pellets, pellet boilers to provide the municipal sector, stimulating credit policy for establishing pellet boilers in the private sector, tariff policy, explanatory work among the population.

Keywords: sustainable development, energy, price, market, bio-resources, pellets, agripellet, pricing factors, calorific value, pellet boilers.

\section{Введение}

Важным фактором развития и коммерциализации биоэнергетических технологий в секторе производства твердого топлива из отходов агропроизводства является ценообразование. Широкое применение агропеллет во многом способствует устойчивости развития экономики страны. Это связано с высокими энергетическими качествами топливных агропеллет, удобством их использования как в промышленной генерации энергии, так и в потребительском секторе, возобновляемостью агроресурсов, 
объективностью возникновения агроотходов, низким екологическим воздействием на всех стадиях производства и потребления (нулевая эмиссия $\mathrm{CO}_{2}$, низкое образование золы, использование золы в качестве минеральных удобрений, современные экологоориентированные технологии производства и сжигания пеллет).

\section{Цели исследования}

Изучить влияние ценообразования на рынке агропеллет на формирование устойчивого развития экономики страны.

\section{Материалы и методы}

Исследование базируется на комплексе общих и специальных методов исследования, которые отражают основные научные принципы, использование современных теоретических концепций и механизмов их имплементации на практике, выявление специфических особенностей украинского рынка топливных пеллет из отходов сельскохозяйственного сырья. Был применен комплекс маркетинговых методов, в том числе на основе главных методов сбора информации (анализ документов, наблюдение, опрос) и производных от них специальных опросных методик (экспертного опроса) осуществлен сбор, уточнение, проверка и анализ первичной информации предприятий- производителей агропеллет в Украине, сформирована база данных по 62 работающим в первом квартале 2015 производителям топливных агропеллет, осуществлена статистическая обработка данных в программном пакете SPSS и в Excel.

В качестве материалов исследования в статье выступают данные государственных органов статистики, данные анкетирования 62 производителей агропеллет в Украине во 2-м квартале 2015 года, нормативно-правовые документы.

\section{Методология}

Современное состояние рынка твердого биотоплива, в том числе агропеллет, в странах с разным уровнем экономического развития рассмотрено в работах многих ученых. Так, К. Хамелинск рассматривал перспективы увеличения потребления твердого биотоплива в Европе [1], Э. Монтейро, В. Манса, А. Рубоа исследовали рынок португальских пеллет, проанализировали производство и ограничения при использовании пеллет [2]. М. Климчук исследовал потенциал рынка твердого биотоплива в Украине, осуществил его оценку, выделил сдерживающие и движущие факторы, основные проблемы и перспективы расширения внутреннего рынка биотоплива [3]. М. Коломийченко, С. Апальков, Т. Игнатенко предлагают пути гармонизации украинских стандартов со стандартами ЕС, обосновывают целесообразность перехода на отопление с использованием твердого биотоплива [4]. Р. Исьёмин, С. Кузьмин, А. Милованов и др. исследуют возможности использования соломы в качестве топлива для коммунальной энергетики России [5].

Многие исследования рынка агропеллет осуществлены через призму взаимосвязи с устойчивым развитием. Например, А. Дансю, В. Влэдут, П. Гажену, А. Пеун, К. Леер изучали возможности снижения загрязнения почв и воды, при использовании твердой биомассы из сельскохозяйственного и лесного сырья [6]. Г. Гелетуха, Т. Железная, а также В. Крамар, П. Кучерук в серии научно-аналитических работ рассматривают перспективы использования отходов сельского хозяйства для производства энергии в мире и в Украине, перспективы развития рынка твердого биотоплива и возможности замещения биотопливом природного газа [7-9]. В. Очеретный, А. Бойко, Д. Харкавый рассматривают применение твердого топлива в контексте энергосбережения в Украине [10]. Однако, изучение влияния ценообразования на рынке агропеллет на формирование устойчивого развития экономики страны не нашли достаточного отражения в современных научных трудах.

\section{Результаты исследования}

Система устойчивого развития экономики страны предполагает такое субъектнообъектное взаимодействие в структуре элементов и компонентов на всех иерархических уровнях, которое обеспечивает экономический рост при стабильных показателях использования исчерпаемых природных ресурсов, минимизацию экологической нагрузки и 
обеспечение самовосстановления экосистем, создание благоприяных условий для развития социального и человеческого капитала. Однако многие внешние и внутренние факторы, такие как флуктуация мировых цен на исчерпаемые энергоресурсы, новые технологические возможности и экологические риски использования неконвенциальных источников энергии, ограничения связанные с изменениями климата, использование странами, крупными субъектами мировой экономики, энергетической инфраструктуры для решения геополитических задач, в комплексе создают вызовы поддержанию динамической устойчивости энергетики и экономики любой страны в глобализированном мире.

Способствует устойчивости развития экономики страны применение биотоплива из отходов сельскохозяйственного производства, поскольку такие отходы неизбежны и их коммерческая реализация сельскохозяйственными производителями способствует собственной устойчивости, а использование агросырья для производства биотоплива повышает устойчивость экономики страны за счет экологизации, самообеспечения энергоресурсами (энергобезопасности и энергонезависимости) и создания рабочих мест. Особое место при этом занимает производство агропеллет, которые по сравнению с другими видами твердого биотоплива не только характеризуются высокими энергетическими качествами, возобновляемостью и экологичностью агроресурсов, но более пригодны для использования в промышленной генерации тепловой и электрической энергии в связи с возможностью беспрерывной подачи в котлы, а также удобны в потребительском, промышленном и коммунальном секторах.

В рыночных условиях развитие рынка агропеллет определяется многими факторами, среди которых важное место занимет ценообразование. Потребительские цены агропеллет формируются в зависимости от многих факторов, которые можно сгруппировать во внитрихозяйственные и внешнехозяйственные, кратко- и долгосрочные. Эти группы факторов являются общими для всех видов топливных пеллет из биосырья, а не только агропеллет.

К внутренним факторам ценообразования относятся:

- производственные особенности (стоимость оборудования, масштабы производства, инвестиционная программа, технологический уровень, объемы прпоизводства);

- вид пеллеты (агропеллета, древесная пилета (из отходов древесины), пилета из растительного сырья (например, из тростника), торфяная пилета, пилета из куриного помета, комбинированная пилета из различных видов сырья (например, из агроотходов и торфа, из древесины и угля) ;

- доступность и наличие стабильного снабжения сырьем;

- качество / сорт топливной пеллеты;

- наличие сертификата на продукцию;

- базовые условия поставки согласно инкотермс (украинские производители топливных пеллет чаще применяют EXW, FCA, DAP, DDU);

- организация производства;

- логистические решения (фасовка, качество тары, транспортные расходы, наличие / отсутствие транспортной и складской инфраструктуры).

Анализ конкретной ситуации, инвестиционных и производственных возможностей компании требует принятия решений по обеспечению биомассой; тары; упаковки; транспортных расходов; складской инфраструктуры. Другими важными факторами, которые влияют на ценообразование, являются текущие цели предприятия и маркетинговая стратегия предприятия. Текущие цели предприятий-производителей топливных пеллет из биосырья должны отражать производственную программу, бюджет, оперативную деятельность, например, по ремонту оборудования.

Внешние по отношению к предприятию цели группируются, в свою очередь, в институциональные, конъюнктурные и природные. К институциональным относятся:

- государственная энергетическая политика - стратегия энергоэффективности и энергетической безопасности за счет замещения импортированного природного газа альтернативными источниками энергии;

- государственная экологическая политика - улучшение экологической ситуации и повышение уровня экологической безопасности, в том числе, за счет оптимизации 
энергетического сектора, реализации основных принципов государственной политики по адаптации к изменению климата, разработка и поэтапное выполнение национального плана мероприятий по смягчению последствий изменения климата;

- государственная валютная политика;

- уровень инфляции.

К конъюнктурным факторам относятся уровень цен, спрос, предложение, перспективы развития рынка. Например:

- предложение на национальном рынке топливных пеллет;

- предложение на экспортном рынке топливных пеллет;

- предложение на региональном рынке топливных пеллет;

- предложение на рынке биосырья;

- предложение на рынке других видов топлива (топочного мазута, природного газа, каменного и бурого угля, торфа, соломы и др.);

- объемы регионального и национального рыночного спроса (введение в действие новых и переоборудование имеющихся котельных малой и средней мощности и электростанций для использования биопеллет, увеличение числа частных потребителей);

- объемы внешнего рыночного спроса (экспорт);

- конкуренция на региональном и национальном рынке;

- наличие трейдеров;

- середнерегиональна цена топливных пеллет;

- середненациональна цена топливных пеллет;

- цены на биосырье;

- среднерегиональные и средненациональные цены других видов топлива (топочного мазута, природного газа, каменного и бурого угля, торфа, соломы и др.);

- средние цены в стране / странах экспорта и тому подобное.

Экспортный потенциал биотопливных пеллет в определенной степени зависит от ценовых значений. Особенности ценообразования на экспортном рынке топливных пеллет из биомассы формируется под влиянием самых разных факторов, среди которых: цены на традиционные энергоносители; государственная энергетическая политика; государственная экологическая политика (в т.ч. направленная на сокращение выбросов парниковых газов); изменения климата и погодных условий, вид пеллеты базовые условия поставки согласно Инкотермс (производители топливных пеллет чаще применяют EXW, FCA, DAP, DDU), логистические решения (фасовка, качество тары, транспортные расходы, наличие / отсутствие транспортной и складской инфраструктуры); маркетинговая стратегия предприятия; длина и ширина каналов распределения.

Факторы, влияющие на спрос и предложение на рынке биотоплива, можно разделить по временному признаку на две группы: краткосрочные и долгосрочные. Краткосрочные действуют в течение одного года, поскольку потребление топливных гранул, как любого другого топлива, имеет сезонный характер. Долгосрочные - определяют тенденции, связанные с изменением емкости рынка в более длительной перспективе.

К краткосрочным факторам, определяющих спрос на биотопливо, относятся:

- появление на рынке новых крупных потребителей (электростанций, котельных и т.п.), например, введение в действие новых и перевода на биотопливо уже существующих крупных электростанций;

- погодные условия и температура воздуха во время отопительного сезона;

- объемы накопленных запасов биотоплива у потребителей и торговцев, например, остатки на складах после теплой зимы;

- текущий уровень цен на другие энергоносители (нефтепродукты, газ, уголь), а также на саму электрическую и тепловую энергию;

- деятельность крупных торговцев биотопливом, например, игра на понижение или повышение с целью захвата большей доли рынка.

С другой стороны, на объем предложения в течение одного года могут влиять:

- производственные возможности действующих биотопливных заводов;

- объемы предложения на рынке сырья для производства биотоплива (древесных отходов и других видов биомассы); 
- появление на рынке новых поставщиков;

- деятельность крупных трейдеров, например, привлечение ими значительных объемов биотоплива, закупаемых на новых рынках.

В долгосрочной перспективе объемы закупок топливных гранул растут под влиянием таких факторов, как:

- государственная и международная политика, направленная на поддержку возобновляемой энергетики и сокращения выбросов парниковых газов;

- конъюнктура углеродного рынка (определяющее влияние на рентабельность многих биоэнергетических проектов в западной европе)

- тенденции на мировых рынках традиционных энергоносителей;

- увеличение количества бытовых котлов и малых котельных на биотопливе, установленных в странах, потребляющих топливные гранулы.

Предложение топливных гранул в долгосрочной перспективе зависит от таких факторов:

- запасы биомассы, пригодной для переработки в биотопливо;

- объемы инвестиций в организацию производства и логистики на рынке биотоплива;

- объемы потребления биотоплива на других топливных рынках.

К природным факторам относятся погодные условия, изменения климата, сезонность (сезонность заготовки биомассы из сельскохозяйственных отходов и сезонность потребления топлива в умеренных широтах).

Стоимость топлива зависит не только от рыночных, внутрихозяйственных, природных и институционально-регулятивных факторов, а также от количества энергии, которую можно получить от его сжигания, то есть от теплотворной способности, теплопроизводительности топлива. Кроме потребительской цены на различные виды топлива имеют значение и другие потребительские характеристики, такие как экологические показатели, возможность автоматизации процесса отопления, доступность вида топлива, экологичность, безопасность и удобство при использовании. Отметим, что каждый из видов топлива может иметь разное качество (сортность), что влияет на потребительские характеристики и цену.

В таблице 1 представлены потребительские цены агропеллет в Украине по сравнению с ценами на другие виды топлива в первой половине 2015 года. Соотношение между основными единицами энергии рассчитано согласно с общепринятым, где 1 килокалория (ккал) = 0,004187 мегаджоуль (МДж).

Таблица 1

\section{Сравнительная характеристика цены агропеллет с ценами на другие виды топлива}

\begin{tabular}{|c|c|c|c|c|c|c|c|}
\hline 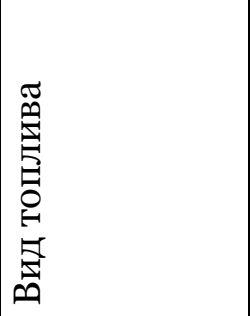 & 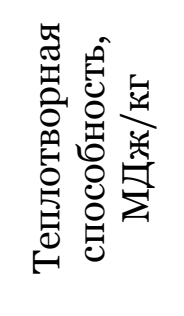 & 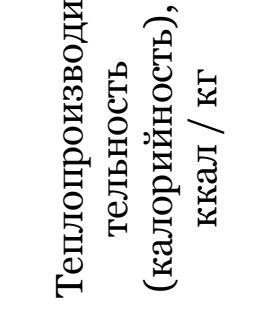 & 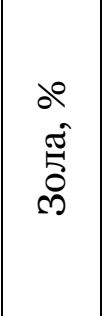 & 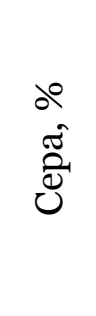 & 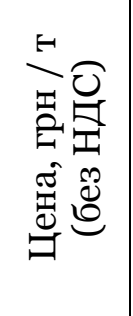 & 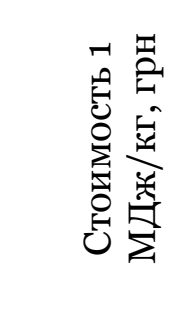 & 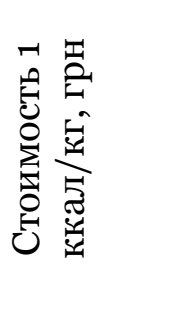 \\
\hline агропеллеты & $14,3-19,5$ & $3415,3-4657,3$ & $\begin{array}{r}0,48 \\
-9,7 \\
\end{array}$ & $\begin{array}{c}0,00 \\
2- \\
0,18 \\
\end{array}$ & $\begin{array}{l}917- \\
2250\end{array}$ & $\begin{array}{c}64,1-115 \\
4\end{array}$ & $0,27-0,48$ \\
\hline \begin{tabular}{|l|} 
дрова \\
(влажность \\
$12 \%)$ \\
\end{tabular} & $15^{-16,8}$ & $3571-4000$ & 2 & $\mathrm{O}$ & $\begin{array}{l}417- \\
485\end{array}$ & $28-29$ & 0,12 \\
\hline $\begin{array}{l}\text { каменный } \\
\text { уголь }\end{array}$ & 22 & $5238-7200$ & \begin{tabular}{|c|}
$10-$ \\
36
\end{tabular} & $\begin{array}{c}0,5^{-} \\
9,3\end{array}$ & $\begin{array}{c}2300- \\
2700\end{array}$ & $105^{-123}$ & $0,38-0,44$ \\
\hline
\end{tabular}




\begin{tabular}{|c|c|c|c|c|c|c|c|}
\hline бурый уголь & $14-23,87$ & $3333-5683$ & \begin{tabular}{|c|}
$10-$ \\
35 \\
\end{tabular} & $3-7$ & $\begin{array}{c}580- \\
750 \\
\end{array}$ & $31-41$ & $0,13^{-0,17}$ \\
\hline $\begin{array}{l}\text { топочный } \\
\text { мазут }\end{array}$ & 39,2 & 9333 & \begin{tabular}{|l|}
0,15 \\
$-0,3$
\end{tabular} & $\begin{array}{c}2,2- \\
3,5\end{array}$ & 5415 & 138 & 0,58 \\
\hline $\begin{array}{l}\text { дизельное } \\
\text { топливо }\end{array}$ & 42,7 & 10167 & \begin{tabular}{|c|}
0,01 \\
- \\
0,02
\end{tabular} & $\begin{array}{c}0,1- \\
0,5\end{array}$ & $\begin{array}{c}16400 \\
- \\
17250 \\
\end{array}$ & $384-404$ & $1,61-1,70$ \\
\hline $\begin{array}{l}\text { природный } \\
\text { газ* }\end{array}$ & 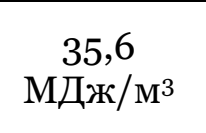 & 8476 (ккал/м³) & $\mathrm{O}$ & $\mathrm{O}$ & \begin{tabular}{|l|}
5990 \\
$(3000)$ \\
-6600 \\
\end{tabular} & $\begin{array}{c}168-185 \\
(84)\end{array}$ & $\begin{array}{c}0,71(0,35) \\
-0,78\end{array}$ \\
\hline торфобрикеты & $15^{-19}$ & $3571-4650$ & \begin{tabular}{|c|}
$17-$ \\
23 \\
\end{tabular} & $\mathrm{O}$ & \begin{tabular}{|c|}
$1100-$ \\
1580 \\
\end{tabular} & 73-105 & $0,31-0,34$ \\
\hline солома & $13,5^{-15,01}$ & $3214-3574$ & 5,0 & $\begin{array}{c}0,16 \\
- \\
0,18\end{array}$ & $\begin{array}{l}650- \\
800\end{array}$ & $48-53$ & $0,20-0,22$ \\
\hline
\end{tabular}

Примечания:

* для населения стоимость природного газа - 7188 (36оо льготная цена) грн за 1000 м $^{3}$ (с НДС) [12-14], соответственно, для населения без НДС стоимость 5990 (3000) грн за $1000 \mathrm{M}^{3}$; для бюджетных учреждений Украины - 6600 грн за 1000 м³ $^{3}$ (без НДС);.

Источник: составлено и рассчитано по данным [12-18].

Заготовка дров в Украине ограничена санитарными рубками и осуществляется не во всех регионах (лесистость территрии существенно отличается в зависимости от природных условий и антропогенной нагрузки на природную среду). Большое содержание серы в буром угле приводит к усиленной коррозии стальных частей котлов, другим негативным фактором является способность бурого угля к самовозгоранию при длительном хранении. По экологическим и потребительским показателям дрова, бурый уголь и солома уступают агропеллетам. Так, показатель зольности дров превышает показатель агропеллет с лучшими характеристиками в 4,2 раза, но по сравнению с худшими характеристиками является лучшим почти в 5 раз; бурый уголь - уступает агропеллетам в 3,6 до 21 раза, а солома - в 48 раз.

По содержанию серы агропеллеты уступают дровам, но имеют гораздо лучший показатель, чем бурый уголь и солома, содержание серы в которых, соответственно от 5 до 70-и от 6 до 59 раз больше содержания серы в агропеллетах. Главной же проблемой при использовании соломы как топлива является ее низкая насыпная плотность (30-40 кг / м3), что подтверждает высокий удельный вес себестоимости транспортировки и хранения соломы, а также усложняет систему подачи соломы в топку котла [171]. Для сравнения, насыпная плотность агропеллет (согласно предоставленных производителями сертификатов) колеблется от 440-1170 кг / м³. При этом производители агропеллет, которые перерабатывают солому в качестве биосырья показали данные по насыпной плотности 640-962,4 кг / м³, т. е. при использовании агропеллет из соломы потребуется в 21 раз меньше площадь помещения для хранения топлива, чем для хранения тюкованой соломы, при этом агропеллеты подаются в котел автоматически, без задействования трудовых ресурсов, что удешевляет затраты на обслуживание системы отопления. Также удаленность предприятия от основных транспортных узлов, поставщиков сельскохозяйственного сырья (наличия в 50-ти километровой зоне сельскохозяйственных произвдителей, обрабатывающих площади посевов зерновых не менее 1000 га), таможни (при экспорте) может значительно повлиять на цену продукции конкретных производителей.

На рисунке 1 представлена средняя цена основных видов топливных пеллет в Украине в грн за 1 т без НДС на условиях поставки EXW (Инкотермс 2010) в первой половине 2015. Для сравнительного анализа были рассмотрены цены на пеллеты из лузги подсолнечника, из соломы, из двух видов древесины (соломы и дуба) и из камыша. Из имеющихся открытых данных и результатов анкетирования было построено рисунок 1 , который демонстрирует, что самую низкую цену имеют пеллеты из лузги подсолнечника, а наивысшую - пеллеты из дуба. Разница в цене между ними составляет 2,5 раза. Высокой является цена на пеллеты из 
камыша. Хотя камыш не требует создания специальных условий для выращивания, вместе с тем, высокая теплотворная способность, особенности размещения и логистики приводят к такой разнице в стоимости.

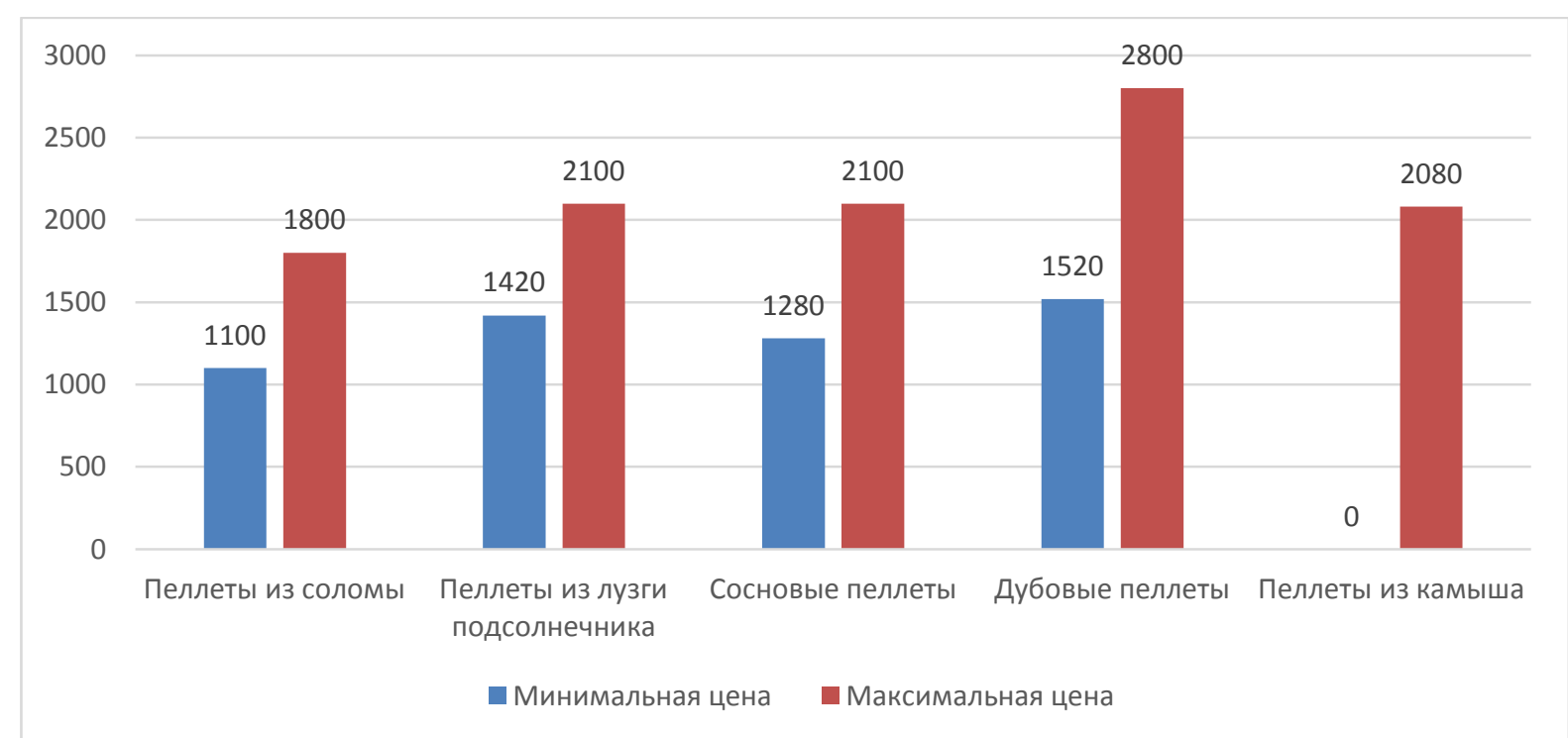

Puc. 1. Средняя цена топливных пеллет по Украине грн. за 1 т без НДС, условия поставки EXW (Инкотермс 2010) в 1 половине 2015 г.

Источник: составлено и рассчитано по данным анкетирования производителей агропеллет.

В таблице 2 представлены не только потребительские цены агропеллет по сравнению с ценами на другие виды топливных пеллет из растительного сырья (биомассы), но и основные характеристики, в частности, теплотворная способность, теплопроизводительность (калорийность), зольность, влажность и содержание серы.

Таблица 2

\section{Сравнение потребительской цены агропеллет с ценами на другие виды топливных пеллет из биомассы с учетом отдельных характеристик, средние цены по Украине за первое полугодие 2015 г.}

\begin{tabular}{|c|c|c|c|c|c|c|}
\hline $\begin{array}{l}\text { Вид топливных } \\
\text { пеллет из } \\
\text { биомассы }\end{array}$ & $\begin{array}{c}\text { Теплотворная } \\
\text { способность, } \\
\text { МДж/кг }\end{array}$ & $\begin{array}{c}\text { Тепло- } \\
\text { производительность } \\
\text { (калорийность), ккал } \\
\text { / кг }\end{array}$ & 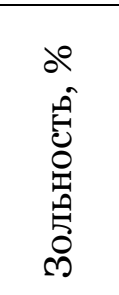 & 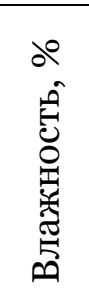 & ڤึ & $\begin{array}{c}\text { Средняя } \\
\text { стоимость } \\
1 \text { МДж/кг } \\
\text { в грн }\end{array}$ \\
\hline $\begin{array}{l}\text { Пеллеты из } \\
\text { соломы }\end{array}$ & $15,5^{-16}$ & $3702-3821$ & $4-6,5$ & $<10$ & - & 71-112 \\
\hline \begin{tabular}{|l|} 
Пеллеты из лузги \\
подсолнечника
\end{tabular} & $17,9-19,9$ & $4275-4738$ & $<2,6$ & $6-8$ & 0,01 & $80-105$ \\
\hline $\begin{array}{l}\text { Древесные } \\
\text { пеллеты, }\end{array}$ & $16,0-19,5$ & $3821-4643$ & $<1,5$ & $<12$ & $<0,08$ & $80-143$ \\
\hline $\begin{array}{l}\text { Пеллеты из } \\
\text { камыша }\end{array}$ & 17,216 & 4113 & 5,1 & 7,6 & 0,06 & 121 \\
\hline
\end{tabular}

Источник: составлено и расчитано по данным анкет производителей и их сертификатов.

По данным таблицы 2 можно сделать вывод, что самую низкую стоимость 1 МДж / кг имеют пеллеты из шелухи подсолнечника, на втором месте пеллеты из соломы, на третьем - 
древесные пеллеты, на последнем (четвертом) месте - пеллеты из тростника.

Однако устойчивое развитие рынка агропеллет имеет ограничение в виде низкого спроса со стороны потребителя, что связано низкой эффектвностью ранее проводимой энергетической политики и экологизации энергетики, недостаточной осведомленностью общества с преимуществами использования биотоплива, коррупционными решениями относительно применения «зелёного» тарифа, а также в связи с потребностью в значительных инфестициях в оборудование.

Установленная суммарная мощность пяти работающих ТЭС / ТЭЦ на биомассе, которые получили право продавать электроэнергию по «зелёному» тарифу, составляла в 2013 г. 17,2 МВт, что свидетельствует о значительном не использованном потенциале. Как показывает успешный зарубежный опыт приток инвестиций в производство тепловой и электрической энергии из биосырья стимулируется за счет четко зафиксированного во времени применения льготного налогообложения и использования тарифной политики. В украинском законодательстве стимулы для развития альтернативной энергетики в силу разных причин, в том числе и коррупционной составляющей, лоббировались для развития, в основном, солнечной энергетики. В то же время низкий тариф при получении электроэнергии из биосырья, не возможность получения «зелёного» тарифа при использовании биопеллет электростанциями, неудовлетворительный инвестиционный климат в стране, высокие общеэкономические риски, в совокупности обусловили низкую заинтересованность инвесторов вкладывать средства в био-ТЭС.

Более благоприятная ситуация на украинском рынке производства тепловой биоэнергии. При этом «специфическими факторами риска при реализации проекта являются:

- тарифная политика по тепловой энергии;

- присоединение к электрическим и тепловым сетям;

- процедура получения «зелёного» тарифа на электроэнергию;

- обеспечение топливной сырьем» [19, с. 7].

Согласно целям утвержденного Национального плана действий по возобновляемым источникам энергии (ВИЭ) «в результате совершенствования технологий в Украине путем строительства и ввода в эксплуатацию новых мощностей биогенерации производство электроэнергии из биомассы может быть увеличено до 1100 ГВт • ч в 2015 году (общей мощностью 250 МВт) и к 4220 ГВт • ч в 2020 году (общей мощностью 950 МВт)» [20] в частном секторе, коммунальной и бюджетной сферах, промышленных и коммерческих потребителей.

\section{Внедрение дополнительного биоэнергетического оборудования для производства энергии в Украине до 2020 г. по сравнению с 2013 г.}

\begin{tabular}{|c|c|c|c|c|}
\hline $\begin{array}{c}\text { Потребители / } \\
\text { Тип оборудования }\end{array}$ & Кол-во, ед. & $\begin{array}{c}\text { Установленная } \\
\text { мощность } \mathrm{MB}_{\mathrm{T}}(+ \\
\left.\mathrm{MBT}_{\mathrm{e}}\right)\end{array}$ & $\begin{array}{c}\text { Замещение } \\
\text { ПГ, млрд } \\
\text { м³/год }\end{array}$ & $\begin{array}{c}\text { Расходы } \\
\text { топлива за } \\
\text { отоп. сезон, } \\
\text { млн т }\end{array}$ \\
\hline \multicolumn{5}{|c|}{ население } \\
\hline $\begin{array}{l}\text { котлы на соломе / } \\
\text { стеблях 1-1о МВтт } \\
\text { Переход населения с } \\
\text { индивидуальных к } \\
\text { системам умеренно } \\
\text { централизованного } \\
\text { теплоснабжения }\end{array}$ & 1300 & 2600 & 1,05 & 3144,96 \\
\hline $\begin{array}{l}\text { Удельный вес от } \\
\text { обцего показателя } \\
\text { для населення }\end{array}$ & $4,2 \%$ & & & \\
\hline \multicolumn{4}{|c|}{ коммунальная и бюджетная сферы } & \\
\hline котлы на соломе/стеблях & 1500 & 3750 & 1,52 & 4536 \\
\hline
\end{tabular}




\begin{tabular}{|c|c|c|c|c|}
\hline 1-10 МВтт & & & & \\
\hline ТЕЦ на соломе/стеблях & 50 & $1770(+300)$ & 0,72 & 2503,87 \\
\hline $\begin{array}{l}\text { ТЕЦ на биомассе } \\
\text { энергетических культур }\end{array}$ & 50 & $1770(+300)$ & 0,72 & \\
\hline $\begin{array}{l}\text { Удельньй вес от } \\
\text { обцего показателя } \\
\text { для коммунальной и } \\
\text { бюджетной сфер }\end{array}$ & $73,8 \%$ & & & \\
\hline \multicolumn{5}{|c|}{ промышленные коммерческие потребители } \\
\hline $\begin{array}{l}\text { котлы на } \\
\text { соломе / стеблях 0,1-1 } \\
\text { МВтт }\end{array}$ & 1190 & 595 & 0,45 & 719,71 \\
\hline $\begin{array}{l}\text { котлы на шелухе } \\
\text { подсолнечника }\end{array}$ & 5 & 40 & 0,15 & \\
\hline $\begin{array}{l}\text { ТЭЦ на шелухе } \\
\text { подсолнечника }\end{array}$ & 7 & $210(+42)$ & 0,08 & \\
\hline $\begin{array}{l}\text { Удельный вес от } \\
\text { общего показателя } \\
\text { для промыиленнъх } \\
\text { коммерческих } \\
\text { потребителей }\end{array}$ & 99,2 & & & \\
\hline ВСЕГО & 34681 & $12485(+756)$ & 5,27 & \\
\hline
\end{tabular}

Источник: соствалено и расчитано на основе [7-9].

По данным крупнейших украинских и европейских производителей отопительных котлов в 2014 г. конечными покупателями на рынке Украины было куплено более 320 тыс. отопительных котлов из этого количества удельный вес твердотопливных котлов составляет 71\% (227 тыс. ед). Основная доля купленных котлов пришлась на твердотопливные котлы в диапазоне мощности 12-20 кВт (хотя газовые котлы используют в диапазоне мощности 1632 кВт, но высокая цена природного газа и угроза прекращения его поставок из России обусловили смещение потребительских приоритетов). Для сравнения в 2013 г. было приобретено в 3,4 раза меньше отопительных котлов, среди которых удельный вес твердотопливных составлял 26\% (95 тыс. ед.).

Трехкратная девальвация национальной украинской валюты в 2014-2015 гг. стала причиной смещения спроса с импортной на отечественную продукцию. Так, выросла доля котлов украинского производстваот количества всех приобретенных отопительных котлов, которая составляет 61\%. Однако в условиях 43\% инфляции в 2015 г., снижения платежоспособности и ликвидности предприятий и домохозяйств, кризиса кредитнобанковской сферы, потенциал рынка агропеллет в Украине остается нереализованным.

\section{Заключение}

На основе анализа условий ценообразования на внутреннем и экспортном рынке агропеллет с учетом качественных характеристик топлива, рыночных, внутрихозяйственных, природных и институционально-регулятивных факторов определены преимущества использования агропеллет для потребителей. Осуществлена сравнительная характеристика цены агропеллет с ценами на другие виды топлива в контексте обеспечения устойчивого развития страны (экологичности, возобновляемости, теплотворной способности, доступности для населения, а также энергетической безопасности).

Основными причинами ограничивающими развития внутреннего спроса на рынке топливаных агропеллет являются ценовые ориентиры использования «зелёного тарифа», сложность и высокая стоимость получения кредитов, высокая инфляция. Первоочередными мероприятиями должны стать: усовершенствование механизма применения «зелёного тарифа» для биоэнергетики, переобоудование ТЭЦ и ТЭС с целью использования топливных агропеллет, массовое обеспечение пеллетными котельными муниципального сектора, стимулирующая кредитная политика для устанавления пеллетных котлов в частном 
секторе, стимулирующая развитие твердотопливной тепловой и электрогенерации тарифная политика, разъяснительная работа среди населения.

\section{Примечания:}

1 Хамелінськ К. Попит на стале біопаливо в EC / К. Хамелінськ // Семінар 3 сертифікації сталості біопалива. К., 2013. [Електронний ресурс]. Режим доступу: http://www.ier.com.ua/files/Projects/2011/1_Biomass/o3.07.2013_presentations/Hamelinck_20 13_07_03_-_EU_demand_for_sustainable_biofuels_-_GIZ_workshop_Kyiv_UA.pdf

2 Monteiro E. Portuguese pellets market: Analysis of the production and utilization constrains / E. Monteiro, V. Monteiro, A. Rouboa // Energy Policy. Volume 42, March 2012, Pages 129-135.

3 Климчук М. М. Розвиток ринку твердого біопалива в Україні / М. М. Климчук // Формування ринкових відносин в Україні. 2012. №2 (129). С.143-147.

4 Коломійченко М. Економічне обгрунтування доцільності переходу на опалення твердим біопаливом. Гармонізація українських стандартів та стандартів ЄC. / М. Коломійченко, С. Апальков, Т. Ігнатенко // Упорядник: «Український Пеллетний Союз». Видання підготовлено за підтримки Європейської програмної ініціативи Міжнародного фонду «Відродження». 2014 р. 46 c.

5 Исьёмин Р. Л. О возможности использования соломы в качестве топлива для коммунальной энергетики / Исьёмин Р.Л., Кузьмин С. Н., Милованов А. В. и др. [Электронный ресурс]. Режим доступа: biocentr.web.tstu.ru/Publikacii/promenergoo6.doc

6 Danciu A. Possibilities of Reducing the Soil and Water Pollution Using Agricultural and Forestry Solid Biomass / Aurel Danciu , Valentin Vlăduţ, Paul Găgeanu, Anişoara Păun, Carol Lehr // Bulletin UASVM Agriculture, 66 (1) / 2009.

7 Гелетуха Г. Г. Перспективи використання відходів сільського господарства для виробництва енергії в Україні / Г.Г. Гелетуха, Т. А.Желєзна // Аналітична записка Біоенергетична асоціація України №7. 2014.

8 Гелетуха Г. Г Перспективи розвитку біоенергетики як інструменту заміщення природного газу в Україні / Г. Г. Гелетуха, Т.А. Желєзна, В.Г. Крамар, П. П. Кучерук // Аналітична записка БАУ №12. 30 червня 2015 р. 23 с.

9 Підготовка та впровадження проектів заміщення природного газу біомасою при виробництві теплової енергії в Україні. Практичний посібник / За ред. Г. Гелетухи. К.: Поліграф плюс, 2015. $72 \mathrm{c.}$

10 Очеретний В.П. Застосування твердого палива - шлях до енергозбереження в Україні / В.П. Очеретний, А.С. Бойко, Д.А. Харкавий // Збірник наукових праць Вінницького національного аграрного університету. № 10. т. 1 (58). 2012. С. 93-98.

11 Development and promotion of a transparent European Pellets Market Creation of a European real-time Pellets Atlas. Advancement of pellets-related European standards. [Электронный peсурс]. Режим доступа: http: //ec.europa.eu/energy/intelligent/ projects/sites/iee-projects/files/projects/documents/pelletslas_pellet_standards.pdf.

12 «Про встановлення роздрібних цін на природний газ, що використовується для потреб населення» Постанова національної комісії, що здійснює державне регулювання у сферах енергетики та комунальних послуг 03.03.2015 № 583 Зареєстровано в Міністерстві юстиції України 03 березня 2015 р. за № 242/26687. [Електронний ресурс]. - Режим доступу : http://www.nerc.gov.ua/?id=14329 aбo http://zakon4.rada.gov.ua/laws/show/zo242-15

13 «Про встановлення граничного рівня ціни на природний газ для установ та організацій, що фінансуються з державного і місцевих бюджетів» Постанова національної комісії, що здійснює державне регулювання у сферах енергетики та комунальних послуг 30.07.2015 № 2103. [Електронний pecypc]. Режим доступу: http://www.nerc.gov.ua $/$ ?id=16869.

14 «Про встановлення граничного рівня ціни на природний газ для промислових споживачів та інших суб’єктів господарювання» Постанова національної комісії, що здійснює державне регулювання у сферах енергетики та комунальних послуг від 30.07.2015 № 2104. [Електронний ресурс]. Режим доступу : http://www.nerc.gov.ua/?id=16870. 
15 Руководство по энергетической статистике // OECD/IEA, rue André-Pascal, France. 192 с. [Електронний ресурс]. Режим доступу: https://www.iea.org/publications /.../statistics _manual_russian.pdf

16 WBA Global Bioenergy Statistics 2014 report. World Bioenergy Association. 39 p. [Электронный ресурс]. Режим доступа: www.worldbioenergy.org

17 Сайт НАК «Нафтогаз України». [Електронний ресурс]. Режим доступу : http://www.naftogaz.com/www/3/nakweb.nsf/o/ooC9EC74CA2AE21BC22570D8003240AE

18 Сайт Державної служби статистики України. [Електронний ресурс]. Режим доступу: www/ukrstat.gov.ua

19 Складова Національного проекту «Енергія природи». Будівництво комплексу теплоелектроцентралі на біомасі. Стисле резюме техніко-економічного обгрунтування. [Електронний ресурс]. Режим доступу: http://www.journal.esco.co.ua /industry/ 2013_5/ art153.pdf

20 Національний план дій 3 відновлюваної енергетики на період до 2020 року, затверджено розпорядженням Кабінету Міністрів України від 1 жовтня 2014 р. № 902-p [Електронний ресурс]. Режим доступу: http://zakon5.rada.gov.ua/laws/show/902-2014$\% \mathrm{D} 1 \% 80$

\section{References:}

1 Xamelinsk K. (2013) Popyt na stale biopalyvo v YeS / K. Xamelinsk // Seminar z sertyfikaciyi stalosti biopalyva. - K., 2013. Available from: http://www.ier.com.ua/files /Projects/2011/1_Biomass/03.07.2013_presentations/Hamelinck_2013_07_03_-_EU_demand _for_sustainable_biofuels_-_GIZ_workshop_Kyiv_UA.pdf

2 Monteiro E. (2012) Portuguese pellets market: Analysis of the production and utilization constrains / E. Monteiro, V. Monteiro, A. Rouboa // Energy Policy. Volume 42, March 2012, Pages 129-135.

3 Kly`mchuk M.M. (2012) Rozvy`tok ry`nku tverdogo biopaly`va v Ukrayini / M. M. Kly`mchuk // Formuvannya ry`nkovy`x vidnosy`n v Ukrayini. - 2012. - \#2 (129). - S.143-147.

4 Kolomijchenko M. (2014) Ekonomichne obg`runtuvannya docil `nosti perexodu na opalennya tverdy`m biopaly `vom. Garmonizaciya ukrayins`ky`x standartiv ta standartiv YeS. / M. Kolomijchenko, S. Apal `kov, T. Ignatenko // Uporyadny`k: «Ukrayins`ky`j Pelletny`j Soyuz». Vy`dannya pidgotovleno za pidtry `mky`Yevropejs `koyi programnoyi iniciaty`vy`Mizhnarodnogo fondu «Vidrodzhennya». 2014 r. -46 s.

5 Is'jomin R. L. O vozmozhnosti ispol'zovanija solomy $\mathrm{v}$ kachestve topliva dlja kommunal'noj jenergetiki / R. L. Is'jomin, S. N. Kuz'min, A. V. Milovanov i dr. Available from: biocentr.web.tstu.ru/Publikacii/promenergoo6.doc

6 Danciu A. Possibilities of Reducing the Soil and Water Pollution Using Agricultural and Forestry Solid Biomass / Aurel Danciu, Valentin Vlăduţ, Paul Găgeanu, Anişoara Păun, Carol Lehr // Bulletin UASVM Agriculture, 66 (1) / 2009.

7 Geletuxa G. G. Perspekty `vy`vy`kory`stannya vidxodiv sil`s `kogo gospodarstva dlya vy`robny`cztva energiyi v Ukrayini / G. G. Geletuxa, T. A. Zhelyezna // Anality`chna zapy`ska Bioenergety`chna asociaciya Ukrayiny` \#7. - 2014.

8 Geletuxa G. G Perspekty`vy` rozvy`tku bioenergety`ky`yak instrumentu zamishhennya pry`rodnogo gazu v Ukrayini / G. G. Geletuxa, T. A. Zhelyezna, V. G. Kramar, P. P. Kucheruk // Anality`chna zapy`ska BAU \#12. - 30 chervnya 2015 r. - 23 s.

9 Pidgotovka ta vprovadzhennya proektiv zamishhennya pry`rodnogo gazu biomasoyu pry` vy ‘robny`cztvi teplovoyi energiyi v Ukrayini. Prakty chny `j posibny`k/ Za red. G. Geletuxy`. K.: Poligraf plyus, 2015. $72 \mathrm{~s}$.

10 Ocheretny `j V.P. Zastosuvannya tverdogo paly`va - shlyax do energozberezhennya v Ukrayini / V.P. Ocheretny`j, A. S. Bojko, D. A. Xarkavy`j // Zbirny`k naukovy`x pracz Vinny`cz `kogo nacional `nogo agrarnogo universy`tetu. № 10. т. 1 (58). 2012 p. C. 93-98.

11 Development and promotion of a transparent European Pellets Market Creation of a European real-time Pellets Atlas. Advancement of pellets-related European standards. Available from: http: //ec.europa.eu/energy/intelligent/projects/sites/iee-projects/files/projects /documents / pelletslas_pellet_standards.pdf. 
12 «Pro vstanovlennya rozdribny`x cin na pry`rodny`j gaz, shho vy`kory`stovuyet`sya dlya potreb naselennya» Postanova nacional 'noyi komisiyi, shho zdijsnyuye derzhavne regulyuvannya u sferax energety 'ky` ta komunal `ny `x poslug 03.03.2015 \# 583 Zareyestrovano v Ministerstvi yusty ciyi Ukrayiny` 03 bereznya 2015 r. za \# 242/26687. Available from: http://www.nerc.gov.ua/?id=14329 aбo http://zakon4.rada.gov.ua/laws/show/zo242-15

13 «Pro vstanovlennya grany`chnogo rivnya ciny` na pry`rodny`j gaz dlya ustanov ta organizacij, shho finansuyut`sya z derzhavnogo i miscevy`x byudzhetiv» Postanova nacional `noyi komisiyi, shho zdijsnyuye derzhavne regulyuvannya u sferax energety 'ky` ta komunal `ny`x poslug vid 30.07.2015 \# 2103. Available from: http://www.nerc.gov.ua/?id=16869.

14 «Pro vstanovlennya grany`chnogo rivnya ciny` na pry`rodny`j gaz dlya promy`slovy`x spozhy `vachiv ta inshy`x sub'yektiv gospodaryuvannya» Postanova nacional `noyi komisiyi, shho zdijsnyuye derzhavne regulyuvannya u sferax energety`ky` ta komunal `ny`x poslug vid 30.07.2015 \# 2104. Available from: http://www.nerc.gov.ua/?id=16870.

15 Energy statistics_manual // OECD/IEA, rue André-Pascal, France. 196 p. Available from: https://www.iea.org/publications/.../statistics_manual.pdf

16 WBA Global Bioenergy Statistics 2014 report. World Bioenergy Association. 39 p. Available from: www.worldbioenergy.org

17 The website of the The National Joint Stock Company Naftogaz of Ukraine. Available from: http://www.naftogaz.com/www/3/nakweb.nsf/o/ooC9EC74CA2AE21BC22570 D800 3240AE

18 The website of the State Statistics Service of Ukraine. Available from: www/ukrstat.gov.ua

19 Skladova Nacional `nogo proektu «Energiya pry`rody`». Budivny`cztvo kompleksu teploelektrocentrali na biomasi. Sty`sle rezyume texniko-ekonomichnogo obgruntuvannya. Available from: http://www.journal.esco.co.ua/industry/2013_5/art153.pdf

20 Nacional `ny`j plan dij z vidnovlyuvanoyi energety`ky` na period do 2020 roku, zatverdzheno rozporyadzhennyam Kabinetu Ministriv Ukrayiny vid 1 zhovtnya 2014 p. \# 902-p Available from: http://zakon5.rada.gov.ua/laws/show/902-2014-\%D1\%80

УДК 339.92

\title{
Ценообразование на рынке топливных агропеллет в системе устойчивого развития
}

1 Любовь П. Гальперина

2 Любовь И. Лукьяненко

\begin{abstract}
${ }^{1}$ Киевский национальный экономический университет имени Вадима Гетьмана, Украина кандидат экономических наук, профессор

E-mail: liubovgalperina@gmail.com

${ }^{2}$ Киевский национальный экономический университет имени Вадима Гетьмана, Украина кандидат экономических наук, доцент

E-mail:moia.kneu@ukr.net
\end{abstract}

Аннотация. В статье проанализированы условия ценообразования на внутреннем и экспортном рынке агропеллет с учетом качественных характеристик топлива, рыночных, внутрихозяйственных, природных и институционально-регулятивных факторов. Осуществлена сравнительная характеристика цены агропеллет с ценами на другие виды топлива в контексте обеспечения устойчивого развития страны (экологичности, возобновляемости, теплотворной способности, доступности для населения, а также энергетической безопасности). Проанализированы сложности формирования и развития внутреннего спроса на рынке топливных агропеллет. Показана важность государственной поддержки развития внутреннего потребления агропеллет и определения ценовых ориентиров с использованием «зелёного тарифа». Первоочередными мероприятиями должны стать: усовершенствование механизма применения «зелёного тарифа» для 
биоэнергетики, переобоудование ТЭЦ с целью использования топливных пеллет, массовое обеспечение пеллетными котельными муниципального сектора, стимулирующая кредитная политика для устанавления пеллетных котлов в частном секторе, тарифная политика, разъяснительная работа среди населения.

Ключевые слова: устойчивое развитие, биотопливо, цена, рынок, биоресурсы, пеллеты, агропеллеты, экспорт. факторы ценообразования, теплотворная способность, пеллетные котлы. 